\title{
MYCETOMA OF THE PALPEBRAL CONJUNCTIVA* $\dagger$ CAUSED BY Allescheria boydii (Monosporium apiospermum).
}

\author{
VASIL PERSAUD AND J. B. M. HOLROYD
}

From the Departments of Pathology and Ophthalmology, University of the West Indies, Kingston, Jamaica

ONLY three cases have been reported in the literature in which the saprophytic soil fungus Allescheria boydii caused ocular infection (Pautler, Roberts, and Beamer, 1955; Gordon, Valloton, and Croffead, 1959; Ernest and Rippon, 1966). In the following case Allescheria boydii was responsible for a mycetoma of the left upper palpebral conjunctiva.

\section{Case Report}

A 44-year-old male Negro was seen on June 6, 1967, with left unilateral symblepharon. He had been employed as a gardener at a hotel in the Blue Mountains for many years. There was no previous history of trauma to the eye, but in 1956 he had been admitted to a general surgical ward of the University Hospital of the West Indies for excision of two lumps, one in the left forearm and the other in the right ankle, both of which he had then had for 2 years. Histological examination of the excised specimens showed abscesses containing microscopic colonies of fungi considered by consultant mycologists to be those of Allescheria boydii.

Examination.-The visual acuity was $6 / 24$ in each eye with the pinhole. The right eye was externally normal.

The left eye showed conjunctival adhesions between the lower lid and the eyeball. The inferomedial aspect of the cornea revealed an irregular area of scarring consistent with a healed corneal ulcer (Fig. 1). This was continuous with the conjunctival adhesions. A large conjunctival fold connected the medial end of the lower palpebral conjunctiva to a brown, spherical swelling which protruded from the edge of the upper lid, just lateral to the upper lacrimal punctum.

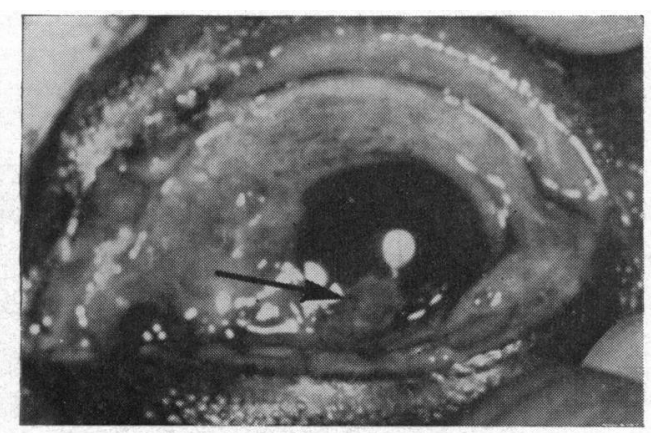

FIG. 1.-Post-operative photograph of left eye showing corneal scar continuous with adherent conjunctival folds (arrow). The site of removal of mycetoma is seen at the margin of the upper lid medially.

Operation.-The adhesions were divided under general anaesthesia in order to establish a deep lower fornix, and the adherent palpebral conjunctiva was dissected free of the cornea. The swelling at the edge of the upper eyelid was completely excised. Post-operatively, tetracycline ointment was applied to the left eye and a glass rod was placed in the fornices to prevent the formation of further adhesions.

* Received for publication November 6, 1967.

+ Address for reprints: as above. 
Pathological Findings. - The excised specimen was a soft, spherical, grey-brown nodule measuring $1 \times 0.5 \times 0.5 \mathrm{~cm}$. It had a smooth surface showing many small lobular extensions. Microscopically, the nodule showed a covering of stratified squamous epithelium. The glands of Moll were markedly dilated and their lumens contained microscopic colonies of fungi. The periductal and periglandular tissues showed severe inflammatory reaction with polymorphonuclear leucocytes, plasma cells, and many foamy macrophages (Fig. 2). The subepithelial tissues at the junction of the palpebral conjunctiva and the skin of the eyelid showed an abscess containing "granules" of fungi with surrounding granulation tissue and fibroblastic reaction (Fig. 3). Special stains of the "granules" revealed a non acid-fast reaction, Gram-positive hyphae and spores, and a positive periodic acid-Schiff reaction.

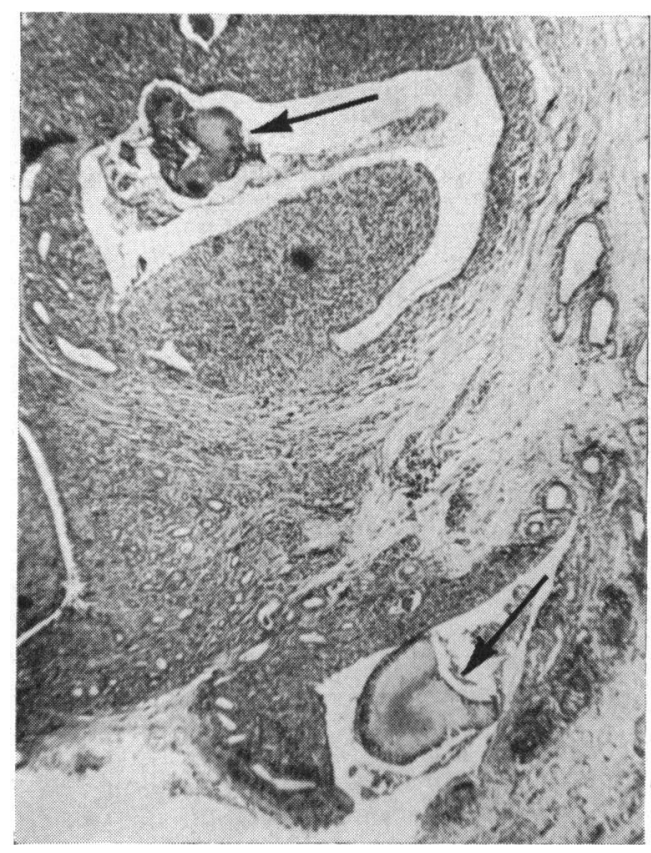

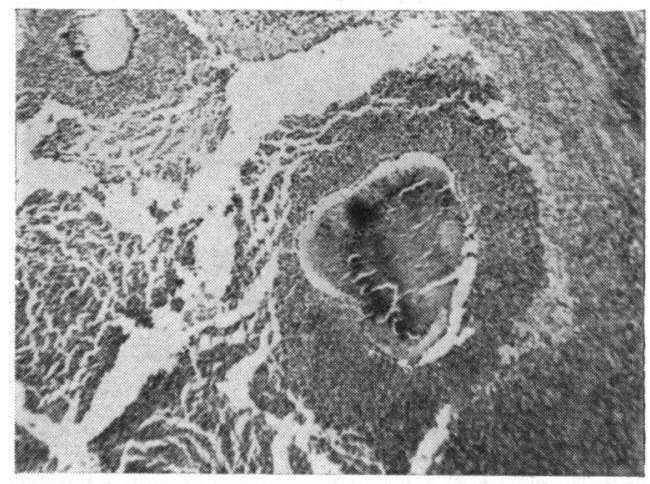

FIG. 3.-Subepithelial abscess containing fungal colonies. Haematoxylin and eosin. $\times 25$.

FIG. 2.-Dilated glands of Moll containing microscopic colonies of fungi (arrows). Note severe periglandular and periductal inflammation. Haematoxylin and eosin. $\times 25$.

Methenamine silver stains demonstrated the typical morphology of Allescheria boydii: branching septate hyphae with round or ovoid conidia borne laterally on short conidiophores and terminally on long conidiophores (Figs 4 and 5, opposite). The spores were located chiefly at the periphery of the fungal colonies.

Mycological Examination.-It was recognized that, since the entire lump was excised and embedded in paraffin, there was little chance of isolating the fungus in culture, but conjunctival scrapings from the area of excision revealed broad septate hyphae and conidiophores consistent with the presence of Allescheria boydii.

\section{Discussion}

In infections with Allescheria boydii, there is a preceding history of trauma to the affected area in more than 50 per cent. of cases (Conant, Smith, Baker, Callaway, and Martin, 1954). Although this was denied by the patient, the possibility of slight unrecognized trauma cannot be excluded. The fungus is most frequently implicated as an aetiological agent in "madura foot". In this connexion it is interesting to note that the patient had previously been infected in the right ankle and left forearm by the same organism. In the 11-year period between the two episodes of infection, he had worked as a gardener in the 


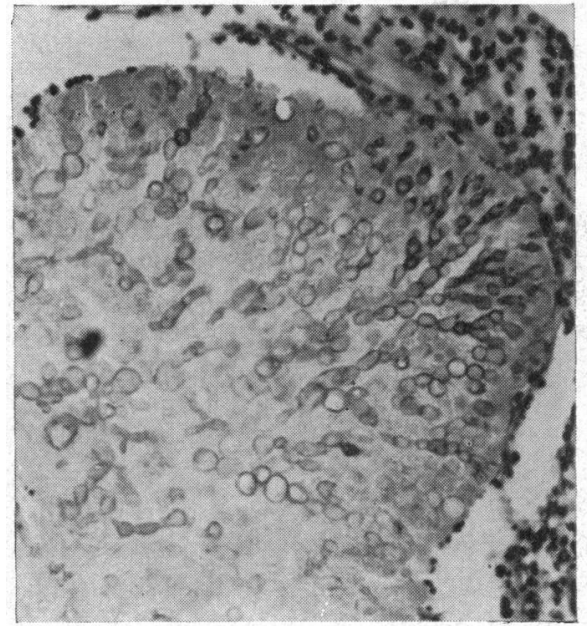

Frg. 4.-Edge of a "granule" at high magnification, showing terminal conidiophores with rounded conidia. Methenamine silver stain.

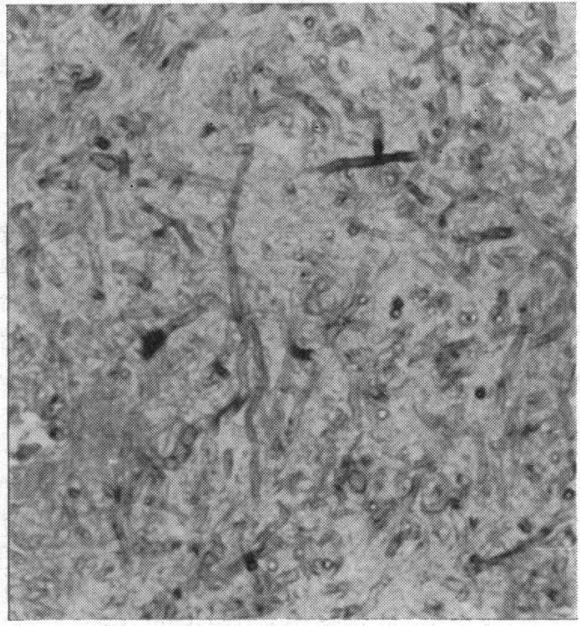

FIG. 5.-Centre of a "granule", showing septate hyphae and spores. Methenamine silver stain. $\times 745$.

same environment, and it is therefore probable that the mycetoma of the eye represented a re-infection and not a spread from the previously infected sites. The left corneal opacity and the associated symblepharon probably indicate that the mycetoma of the palpebral conjunctiva was secondary to a previous keratitis caused by the same fungus.

In haematoxylin-eosin stained histological sections, the microscopic colonies of Allescheria boydii resemble those produced by species of Actinomyces and Nocardia. In special stains for fungi, however, the latter two groups of organisms show branching filaments without spores.

\section{Summary}

Mycetoma of the left upper palpebral conjunctiva due to Allescheria boydii is reported in a 44-year-old male Negro gardener. The infection was associated with symblepharon and corneal scarring. This appears to be the fourth reported case of mycotic infection of the eye caused by Allescheria boydii and the first in which the organism had produced a mycetoma of the conjunctiva.

We are grateful to our colleagues in the Departments of Pathology and Microbiology for their opinion on the identity of the fungus. We should also like to thank Mr. D. W. Degazon, consultant ophthalmologist, for permission to publish the case.

\section{REFERENCES}

Conant, N. F., Smith, D. T., Baker, R. D., Callaway, J. L., and Martin, D. S. (1954). "Manual of Clinical Mycology", 2nd ed., p. 240. Saunders, Philadelphia.

ERnest, J. T., and RIPPON, J. W. (1966). Amer. J. Ophthal., 62, 1202.

Gordon, M. A., Vallotton, W. W., and Croffead, G. S. (1959). A.M.A. Arch. Ophthal., 62, 758.

Pautler, E. E., RoberTs, R. W., and Beamer, P. R. (1955). I Ibid., 53, 385. 